Jean A. Doumit ${ }^{1}$, Samar C. Sakr ${ }^{2}$

\title{
TOWARD A SNOW MELT PREDICTION MAP OF MOUNT LEBANON
}

\begin{abstract}
An important remote sensing task is to delineate snow cover. The global significance of snow patterns constitutes an important part of the climate and bio system of the Earth. Snow contributes to the hydrologic cycle through precipitation storage and melting. It is also important to monitor snow cover lands, and detect its boundaries from the Normalized Difference Snow Index (NSDI).

In this work, based on remote sensing methods we delineate the snow cover on Mount Lebanon from 2013 till 2018 basing on sequential Landsat OLI/TIRS data.

Beside snow cover delineation we extracted terrain characteristics of these snow boundaries from the Digital Elevation Model AW3D30, elevation interval, slope, aspects, insolation calculated for a climatological snow melt analysis and understanding.

The relation of snow covers with terrain morphology is an important climatological factor influencing on the snow position, duration and melting. In this study we are seeking a link between the available snow covers and the terrain parameters.

As a final result of this study based on NDSI index of the Landsat Oli images, a snow duration map of mount Lebanon was built, and the analysis showed that the surface of the snow-cover decreases around spring and it depends directly on the orientation of the slopes especially them which are in full sun and those which are with the shelters.
\end{abstract}

KEYWORDS: snow cover, Landsat, NSDI

\section{INTRODUCTION}

The situation of Lebanon on the Mediterranean Sea and its terrain specific nature with an interval of elevations varying from 0 to 3080 meter above the sea level and the influence of the climate on this terrain factors gave it a cold winter with a temporary snow cover [Doumit, 2017].

Temporary and seasonal snow covers do not survive the summer the case of Lebanon, typically, a seasonal snow cover will survive for several months, usually being replenished throughout the winter, while a temporary snow cover survives for a matter of days.

Over the years, scientists used remote sensing to describe the geographic distribution of snow cover and simplify its mapping, field surveys have been used to generate snow maps [Brown, Braaten, 1998]. With the evolution of geomatics, we used remote sensing feature indexes of snow detection such as Normalized Difference Snow Index (NSDI).

From here, begin the importance of snow cover monitoring and the way of its extraction. First remote sensing methods for snow cover detection and delineation were the unsupervised, supervised classifications using multispectral bands, the tasseled cap transformation (TCB) and may others [Doumit, 2017].

In our study, twenty satellite images of several dates from 2013 till 2018 translated to snow covers based on NSDI for understanding the snow melt process and analyzing the climatological relations with terrain parameters elevation interval, slope, aspect, insolation duration and solar insolation.

\footnotetext{
${ }^{1}$ Lebanese University, department of geography, Faculty of Literatures and Human sciences, Fanar, Lebanon, e-mail: jeandoumit@gmail.com

${ }^{2}$ Lebanese University, department of geography, Faculty of Literatures and Human sciences, Fanar, Lebanon, e-mail: samarsakr2005@hotmail.com
} 


\section{STUDY AREA}

The study area begins from 1300 meters above the sea level to Qornet es Sawda the highest point in Lebanon 3088 m englobing Jezzine highlands, Barouk, Sannine and ending at Amouaa at a length of $130 \mathrm{~km}$.

Figure 1 showed the study area with five intervals of elevation classification hihlighting the decrease in elevation from the North toward the South.

This area is on the north edges of the subtropical high pressures (cell of Hadley connects), near the large Africa and Arabian deserts (the Sahara). In summer, the influence of the subtropical high pressures, (present in altitude) prevent any ascent of air and cause an absolute drought from June to September (fig.1). On the surface (with the sea level), all Eastern Mediterranean is under the influence of a low thermal pressure.

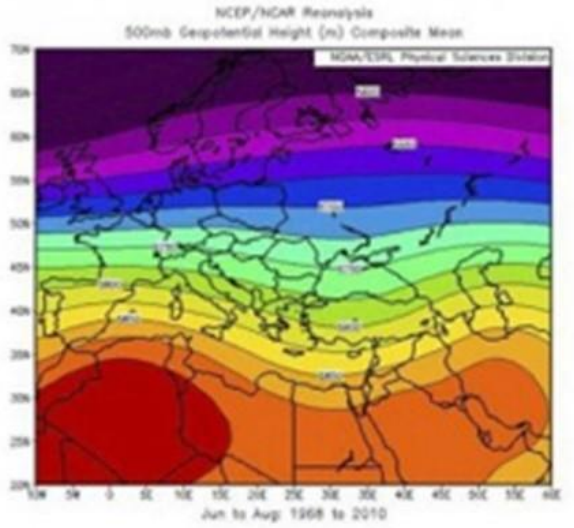

En altitude
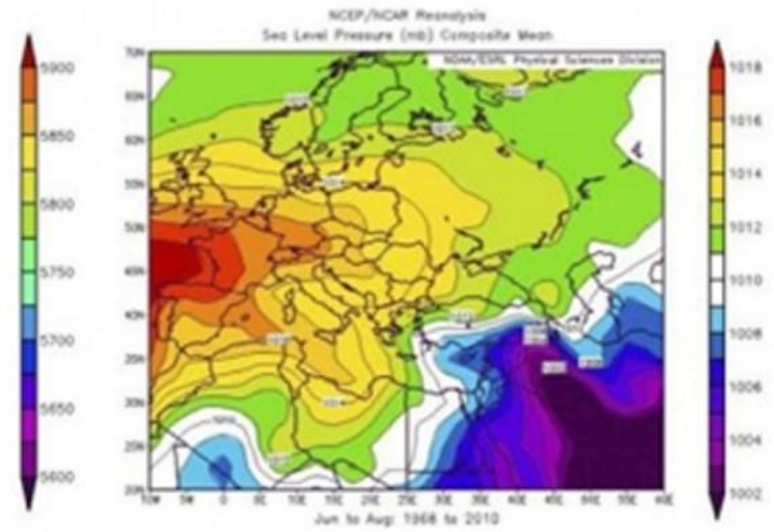

En surface

Fig. 1. Pressure in altitude (500 $\mathrm{hPa}$, on the left) and in surface (on the right) for summer period according to the NCEP/NCAR (from 1990-2017)

During the rainy season, from October to May, the area is subjected, in altitude, with a circulation of west (moderate influences) materialized by subtropical Jet Stream whereas a trough of low pressure covers the Mediterranean (fig. 2). This flow is zonal (fast circulation of the Jet, 150 to $500 \mathrm{~km} / \mathrm{h}$ ) or undulating (slow circulation of the jet, speed $<150 \mathrm{~km} / \mathrm{h}$ ), making alternate periods of good weather and disturbed time (fig. 3 and 4).
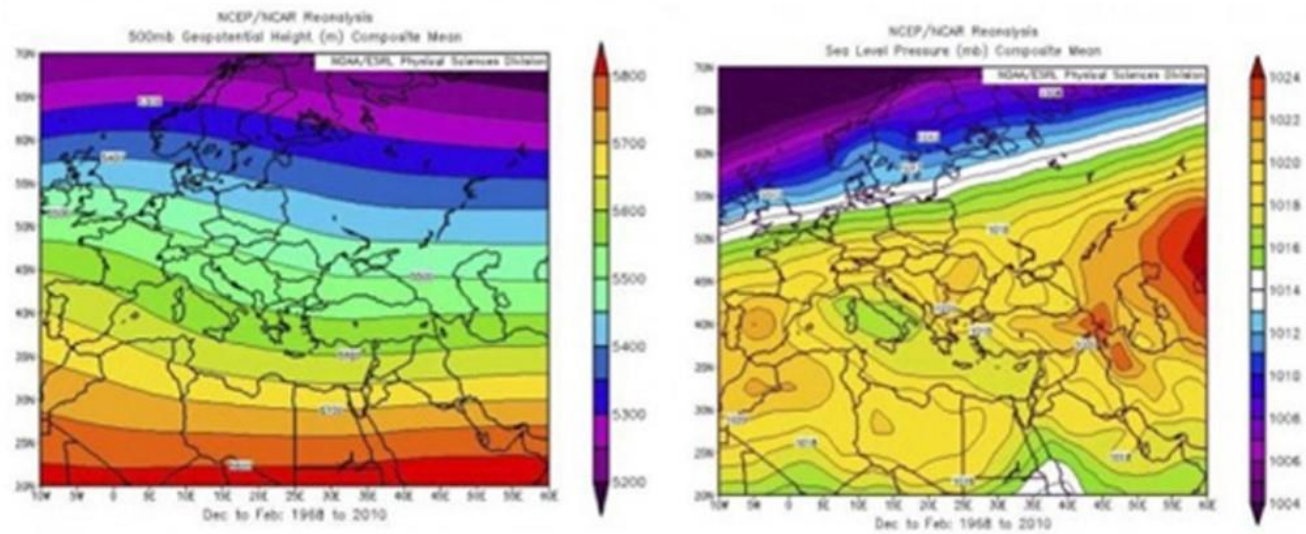

Fig. 2. Pressure in altitude ( $500 \mathrm{hPa}$, on the left) and in surface (on the right) for winter period (according to the NCEP/NCAR from 1990-2017) 

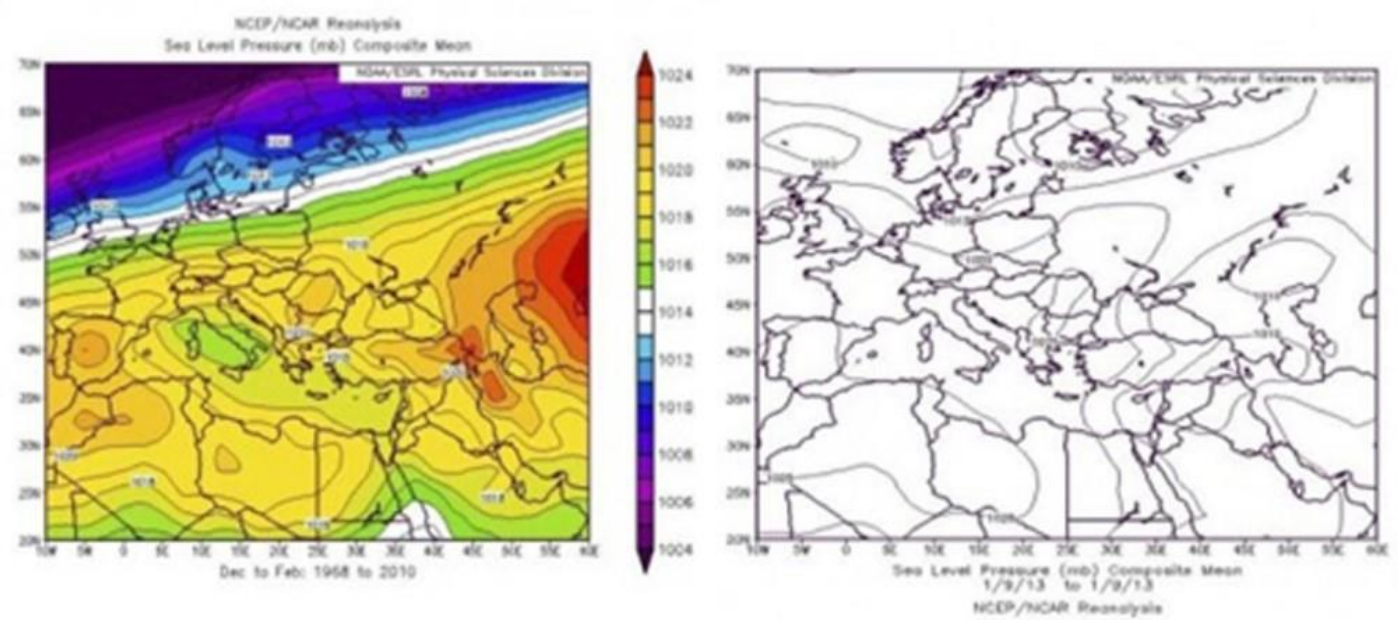

Fig. 3. Example of disturbed circulation above the area (in altitude on the left and the surface on the right) according to the data NCEP/NCAR
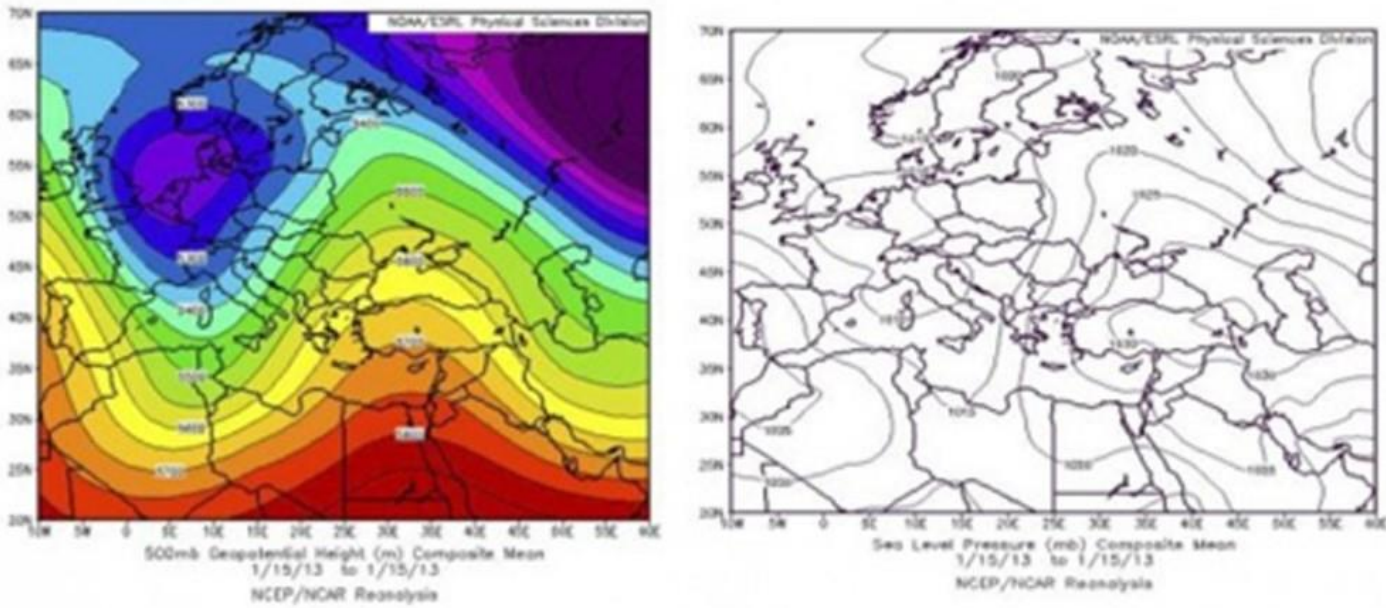

Fig. 4. Example of anticyclone circulation above the area (in altitude on the left and the surface on the right) according to the data NCEP/NCAR

Precipitations concentrate over the months of the rainy season (from October to May with more than $50 \%$ of the annual total during the winter months, December, January and February). Factors geographical (altitude, latitude and continentally; effect of shelter) induce a very strong space variability of the temperatures and particularly of precipitations. These last decreases according to a west-east and south-eastern gradient (effect of continentally and shelter) and NorthSouth (effect of latitude), the disturbances being less and less fed in cold air. The annual pluviometry totals, which are around $800 \mathrm{~mm}$ on the northern littoral of the area, rise with more than 1800 $\mathrm{mm}$ on the summits of Mount-Lebanon to fall to less than $50 \mathrm{~mm}$ towards the south (Negev) on the borders of Arabian desert.

The study area was delineated from the closed contour line with elevation $1300 \mathrm{~m}$ above the sea level with a total area of 1896.97 square kilometer, paralleling the Mediterranean coast for about (15 to $25 \mathrm{~km}$ ), with northern outliers extending into Syria. 


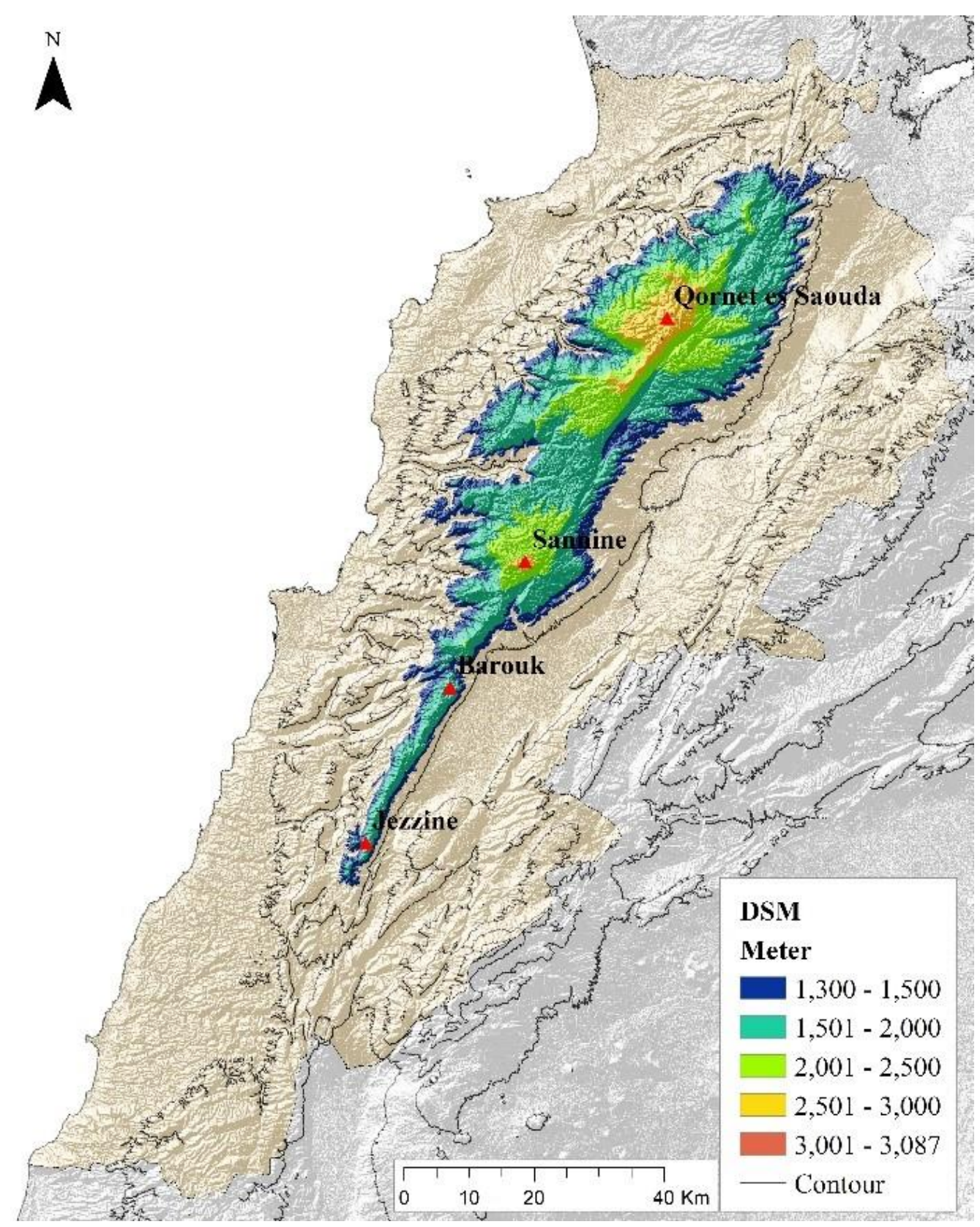

Fig. 5. The map of Lebanon with the study area elevation interval

\section{MATERIALS AND METHODS OF RESEARCH}

Snow cover detection using satellite imagery is a complicated process that must take into account the reflectance values of some of the bands of the electromagnetic spectrum. For this study, images are taken from the Landsat OLI/TIRS. Landsat 8 carries two instruments: The Operational Land Imager (OLI) collects image data for nine shortwave spectral bands with a $30 \mathrm{~m}$ spatial resolution and a panchromatic band used for a pan sharpening.

Landsat swath covers an area of $185 \times 185 \mathrm{~km}$ and Lebanese mountain chain is elongated and needs two images that is why a mosaic was done to convert the whole study area. Datasets were taken from 20 images beginning from 2013 till 2018 (fig. 6).

Landsat 8 data downloaded from the Center for Earth Observation and Digital Earth (CEODE, http://www.ceode.cas.cn/) or the Earth Resources Observation and Science Center (EROS, http://glovis.usgs.gov/). 
The digital numbers of all images were pan sharped to a spatial resolution of 15 meter and converted to surface reflectance to obtain the Top of Atmosphere (TOA) reflectance as suggested by [Smith et al., 2013], using reflectance rescaling coefficients found with Landsat 8 in the product metadata file. The below equation is used for the conversation of digital numbers DN values to TOA reflectance for OLI data as follows ${ }^{1}$ :

$$
\mathrm{TOA}=\frac{\mathrm{MDN}+\mathrm{A}}{\sin \theta}
$$

Where:

$\mathrm{M}=$ Band-specific multiplicative rescaling factor found inside from the Metadata file;

$\mathrm{A}=$ Band-specific additive rescaling factor from the metadata file;

$\mathrm{DN}=$ bands pixel values;

$\theta=$ Local sun elevation angle in degrees from the metadata file.

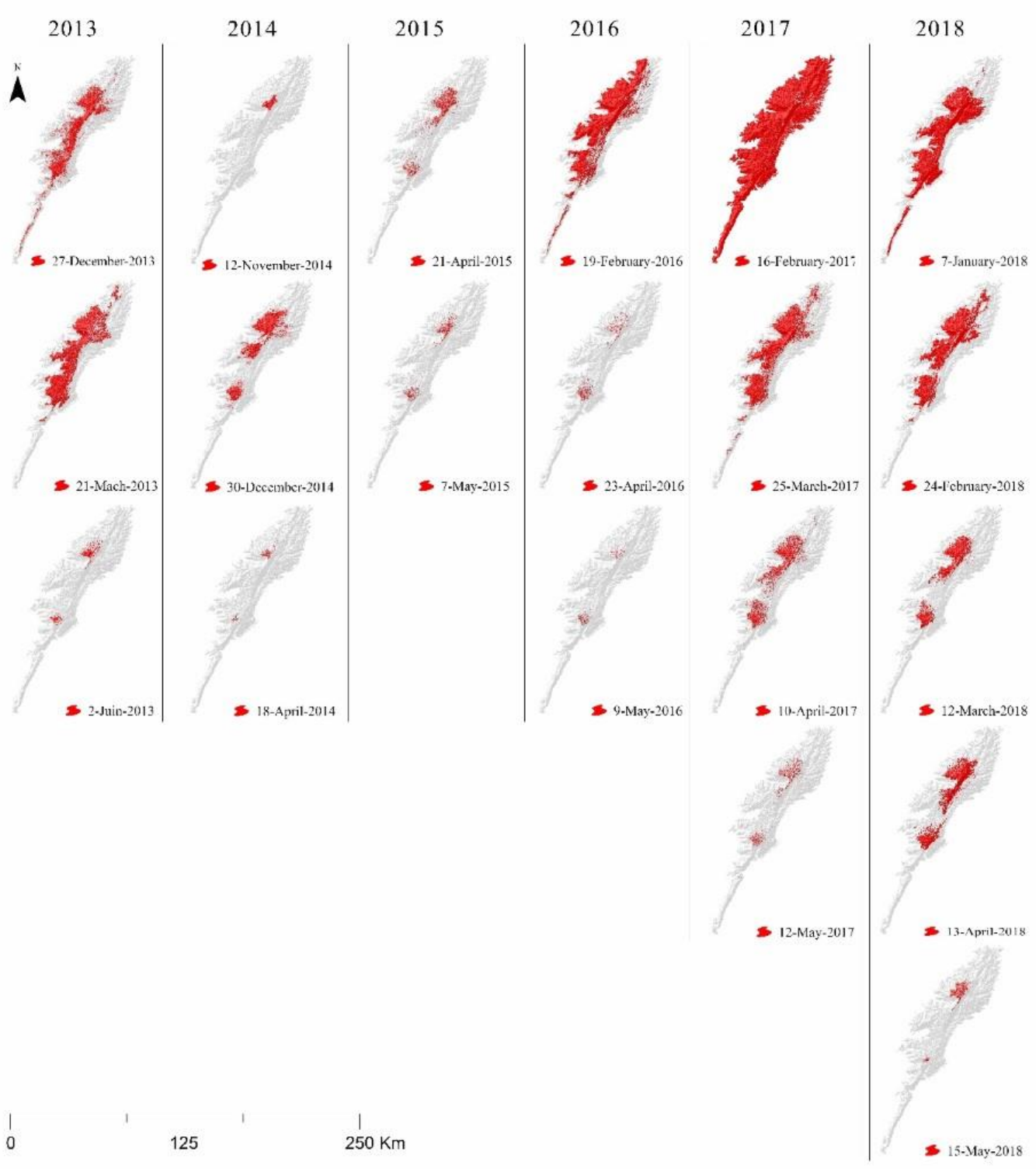

Fig. 6. Snow cover maps of 2013,2014,2015,2016, 2017 and 2018

${ }^{1}$ USGS, Using the USGS Landsat 8 product. Web resource: https://landsat.usgs.gov/Landsat8_Using_Product.php (accessed 13.07.2013) 
After the TOA calculation for all of corresponding Landsat 8 bands, we applied a contrast stretch algorithm by expanding the range of pixel values used to 255 for the enhancement of the brightness in snow pixels.

For the detection of snow cover, we applied the Normalized Difference Snow Index: one of the most successful techniques of snow mapping is the Normalized Snow Difference Index (NSDI) proposed by [Hall et al., 1995]. This technique exploits the high reflectance of snow in the green and the shortwave infrared wavelength bands.

NSDI is calculated using the reflectance values [Hall et al., 1987, 1995]:

$$
\mathrm{NSDI}=\frac{\mathrm{TOA}_{\mathrm{Green}}-\mathrm{TOA}_{\mathrm{SWIR}}}{\mathrm{TOA}_{\mathrm{Green}}+\mathrm{TOA}_{\mathrm{SWIR}}}
$$

A raster calculation operation was done using raster calculator algorithm for the application of mathematical formulas to calculate the index.

Firstly, we perform a calculation using equation (2) of Normalized Snow differential index (NSDI) as recommended by [Hall et al., 1995], [Kulkarni et al., 2006] and [Xiao et al., 2002], we used a NDSI threshold of greater than 0.4 for the detection of snow cover.

The NSDI pixels in the final image are classified into non-snow and snow pixels (fig. 6).

Cloud cover as we know has a big reflectance degree very similar to the snow one, and gives a difficult in snow delineation all the 20 images used in our project has less than $15 \%$ cloud coverage.

For this reason, we see in figure 6 an uncontimuity in the dates, for 2015 only two images for 2013, 2014 and 2016 three images. In 2017 and 2018 approximately all months were covered. The availability of images due to the temporal resolution and to cloud cover of the scene.

Table 1. Snow cover areas related to the acquisition date of satellite image

\begin{tabular}{|c|cc|}
\hline Snow cover date & Area, \% & Area, km \\
\hline 27 December 2013 & 23.95 & 454.35 \\
21 March 2013 & 30.75 & 583.37 \\
2 June 2013 & 2.92 & 55.33 \\
12 November 2014 & 1.59 & 30.21 \\
30 December 2014 & 15.13 & 287.03 \\
18 April 2014 & 1.03 & 19.55 \\
21 April 2015 & 7.49 & 142.15 \\
7 May 2105 & 2.93 & 55.6 \\
19 February 2016 & 45.25 & 858.3 \\
23 April 2016 & 2.97 & 56.35 \\
9 May 2016 & 1.26 & 23.87 \\
16 February 2017 & 93.85 & 1780.23 \\
25 March 2017 & 33.13 & 628.46 \\
10 April 2017 & 14.95 & 283.52 \\
12 May 2017 & 3.92 & 74.41 \\
7 January 2018 & 41.67 & 790.52 \\
24 February 2018 & 32.01 & 607.31 \\
12 March 2018 & 13.17 & 249.9 \\
13 April 2018 & 6.17 & 117.01 \\
15 May 2018 & 2.73 & 51.76 \\
\hline
\end{tabular}


The number of satellite images available for 2015 is two, for 2013 and 2014 three images, a full range of images for 2017 and 2018.

We can see from table 1 that the area of the snow cover increases in winter and begins by decreasing in spring with the month of April, the maximum snow area in all months of April during the last five years is not passing $15 \%$ from the whole study area approximately $283.53 \mathrm{~km}^{2}$.

The peak of the snow cover was in February 2017 with approximately $94 \%$ we can say covering all the study area and more.

Beside Landsat OLI images, the elevation dataset used is from the Japan Aerospace Exploration Agency (JAXA) released "ALOS World 3D - 30m (AW3D30)", the global digital surface model (DSM) dataset with a horizontal resolution of approx. 30-meter mesh $(1 \times 1$ arc second $)$, free of charge. The AW3D30 have been utilized in a wide variety of applications such as map development, damage prediction of natural disasters, and water resource investigation [Tadono et al., 2016].

\section{RESULTS OF RESEARH AND DISCUSSION}

The relation of snow covers with terrain morphology is an important climatological factor influencing on the snow position, duration and melting. In this study we are seeking a link between the available snow covers and terrain parameters such: elevation, slope, aspect, insolation and insolation duration (fig. 7).
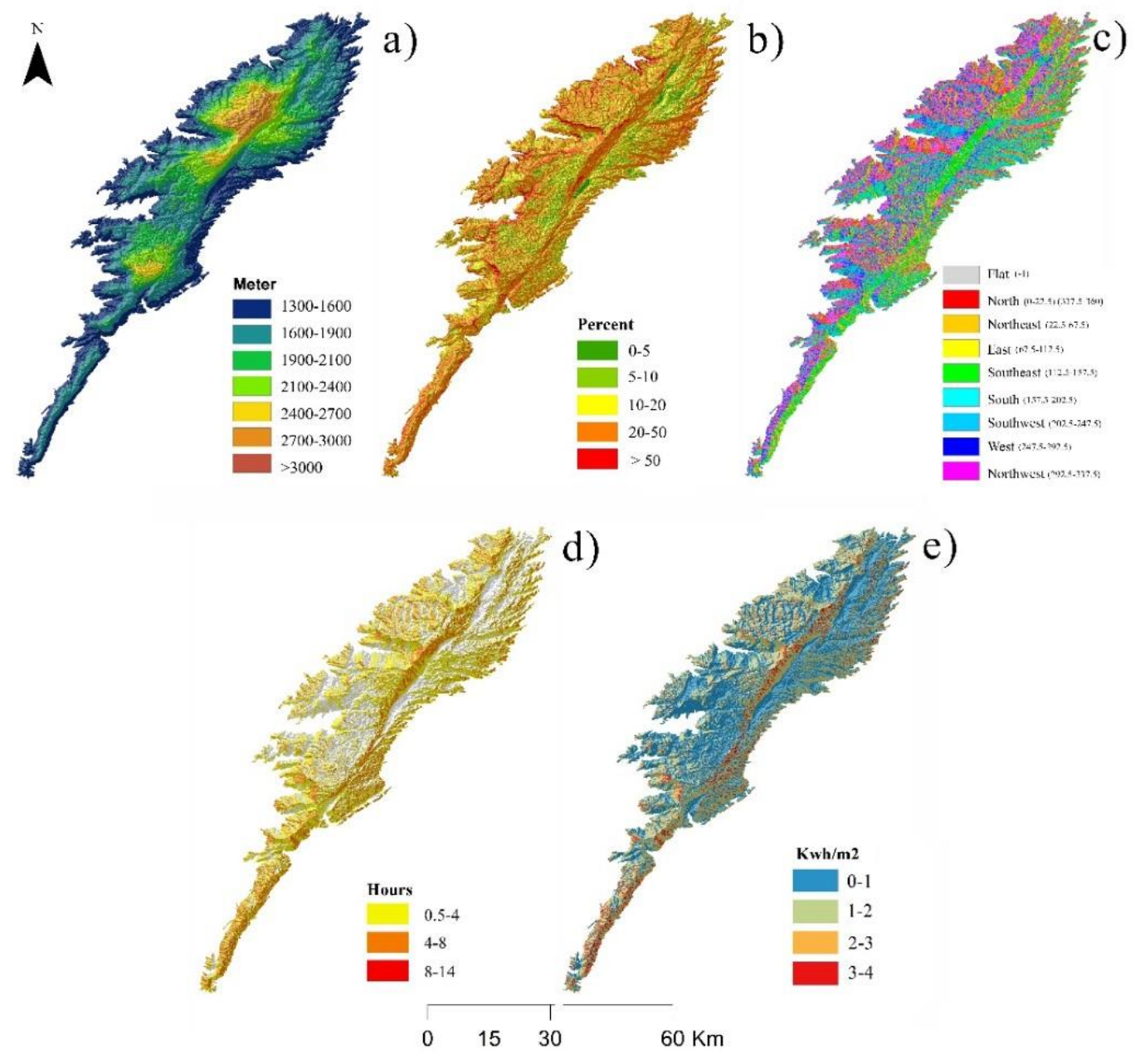

Fig.7. Terrain parameters maps of the study area:

a) elevation interval, b) slope percentage, c) aspect, d) insolation duration, e) insolation 
The DSM of the study area classified with an equal interval of 300 meters forming seven classes, the percentage of slope map generated in ArcMap classified in five classes from low to extreme terrain with slopes higher than $50 \%$. All terrain slopes are classified in all orientations.

The Solar radiation duration of the study area vary from 0 to 14 hours on the top of the hills in figure $3 \mathrm{~d}$ the solar duration map classified in three classes low moderate and high solar duration.

The insolation is measured by kilo watt hour by square meter, the insolation strength varies from 0 to maximum $4 \mathrm{kwh} / \mathrm{m}^{2}$.

All classified terrain indices were cropped with each date of the snow cover to understand how the snow cover melting is acting with the relief.

The first calculated terrain index is the elevation interval of the study area, table 2 showing the areas of each interval of elevation covered by snow.

Table 2. Percentage areas of the elevation interval

\begin{tabular}{|c|c|c|c|c|c|c|c|}
\hline \multirow[b]{2}{*}{ Snow cover date } & \multicolumn{7}{|c|}{ Elevation interval areas, \% } \\
\hline & $1300-1600$ & $1600-1900$ & $1900-2100$ & $2100-2400$ & $2400-2700$ & $2700-3000$ & $>3000$ \\
\hline 27 December 2013 & 0.61 & 5.07 & 5.41 & 6.33 & 4.06 & 2.38 & 0.06 \\
\hline 21 March 2013 & - & 2.78 & 4.63 & 5.44 & 3.50 & 1.74 & 0.03 \\
\hline 2 June 2013 & - & - & - & 0.39 & 1.17 & 1.29 & 0.02 \\
\hline 12 November 2014 & - & - & - & - & 0.03 & 1.49 & 0.07 \\
\hline 30 December 2014 & 0.08 & 0.60 & 2.90 & 5.47 & 3.72 & 2.30 & 0.07 \\
\hline 18 April 2014 & - & - & - & 0.07 & 0.31 & 0.65 & 0.11 \\
\hline 21 April 2015 & - & 0.09 & 0.67 & 1.94 & 2.69 & 2.03 & 0.06 \\
\hline 7 May 2105 & - & - & 0.07 & 0.65 & 0.92 & 1.22 & 0.07 \\
\hline 19 February 2016 & 2.36 & 16.26 & 10.95 & 8.39 & 4.57 & 2.62 & 0.08 \\
\hline 23 April 2016 & - & - & 0.30 & 0.97 & 0.99 & 0.70 & 0.02 \\
\hline 9 May 2016 & - & - & 0.01 & 0.38 & 0.46 & 0.40 & 0.01 \\
\hline 16 February 2017 & 31.17 & 30.53 & 14.96 & 9.87 & 4.70 & 2.43 & 0.06 \\
\hline 25 March 2017 & 0.42 & 8.63 & 9.22 & 8.02 & 4.41 & 2.35 & 0.07 \\
\hline 10 April 2017 & - & 0.87 & 3.66 & 4.94 & 3.44 & 1.99 & 0.04 \\
\hline 12 May 2017 & - & 0.02 & 0.10 & 1.15 & 1.47 & 1.15 & 0.03 \\
\hline 7 January 2018 & 0.94 & 13.36 & 11.36 & 8.90 & 4.48 & 2.55 & 0.08 \\
\hline 24 February 2018 & 0.02 & 5.74 & 11.04 & 8.32 & 4.45 & 2.38 & 0.06 \\
\hline 12 March 2018 & - & 0.05 & 1.90 & 4.78 & 4.10 & 2.29 & 0.06 \\
\hline 13 April 2018 & 0.01 & - & - & 1.15 & 2.74 & 2.19 & 0.07 \\
\hline 15 May 2018 & - & - & - & 0.05 & 1.10 & 1.53 & 0.04 \\
\hline
\end{tabular}

Starting from 2100 meters altitudes we notice that snow persists until spring (May) with different intervals related to the thickness from the snow-covered cover, the temperature which decreases with altitude the exposure of the slopes, the sunning. While at altitudes lower than 2100 meters the snow-covered cover is absent starting from March 2013 and April 2014, 2015 that is due initially to the anticyclone situations (situation of stability) which swept the area, and the temperatures which are higher at these altitudes. temperature data recorded from 8 different stations at different elevation levels were applied to obtain zonal temperature by extrapolating the station altitude to mean zone altitude with a certain temperature lapse rate. The relation between elevation and daily average temperature was developed for different stations. Temperature laps rate estimated is $5.6^{\circ} \mathrm{C} / \mathrm{km}$.

Slope aspect is known to play a major role in snow distribution [Elder et al., 2000; Marofi et al., 2011]. We notice that the accumulation of the snow cover is tiny on lower slopes $<5 \%$ and higher $>50 \%$ compared to the other classes. Accumulation maximum is recorded towards the slopes going from $20 \%$ to $50 \%$ in our study area (table 3 ). 
Table 3. Slope divided into three groups, $\%$

\begin{tabular}{|l|ccccc|}
\hline & \multicolumn{5}{|c|}{ Slope, \% } \\
\multicolumn{1}{|c|}{ Snow cover } & $\mathbf{0 - 5}$ & $\mathbf{5}-\mathbf{1 0}$ & $\mathbf{1 0 - 2 0}$ & $\mathbf{2 0 - 5 0}$ & $\mathbf{> 5 0}$ \\
\hline 27 December 2013 & 1.2 & 2.9 & 7.5 & 11.1 & 1.0 \\
21 March2 013 & 1.3 & 3.5 & 9.7 & 15.2 & 1.0 \\
2 June 2013 & 0.1 & 0.3 & 0.9 & 1.7 & 0.0 \\
12 November 2014 & 0.1 & 0.2 & 0.6 & 0.8 & 0.5 \\
30 December 2014 & 0.5 & 1.6 & 4.7 & 7.8 & 0.5 \\
18 April 2014 & 0.0 & 0.1 & 0.3 & 0.6 & 0.0 \\
21 April 2015 & 0.2 & 0.6 & 1.9 & 4.5 & 0.4 \\
7 May 2105 & 0.1 & 0.2 & 0.8 & 1.8 & 0.1 \\
19 February 2016 & 1.6 & 4.3 & 12.8 & 24.1 & 2.4 \\
23 April 2016 & 0.1 & 0.3 & 0.8 & 1.8 & 0.1 \\
9 May 2016 & 0.0 & 0.1 & 0.3 & 0.7 & 0.0 \\
16 February 2017 & 3.8 & 9.1 & 27.0 & 47.5 & 5.2 \\
25 March 2017 & 1.2 & 3.4 & 9.9 & 17.0 & 1.7 \\
10 April 2017 & 0.6 & 1.6 & 4.4 & 7.8 & 0.6 \\
12 May 2017 & 0.1 & 0.4 & 1.2 & 2.1 & 0.1 \\
7 January 2018 & 1.7 & 4.8 & 13.1 & 20.2 & 1.8 \\
24 February 2018 & 1.2 & 3.4 & 10.0 & 16.4 & 1.1 \\
12 March 2018 & 0.5 & 1.3 & 3.8 & 7.2 & 0.5 \\
13 April 2018 & 0.2 & 0.5 & 1.8 & 3.4 & 0.2 \\
15 May 2018 & 0.1 & 0.3 & 0.9 & 1.5 & 0.0 \\
\hline
\end{tabular}

Table 4. Aspect areas

\begin{tabular}{|c|ccccccccc|}
\hline & \multicolumn{10}{|c|}{ Aspect areas, \% } \\
Snow cover & Flat & North & Northeast & East & Southeast & South & Southwest & West & Northwest \\
\hline 27 December 2013 & 0.01 & 4.66 & 2.61 & 2.16 & 2.15 & 1.88 & 2.37 & 3.33 & 4.77 \\
21 March 2013 & - & 5.07 & 3.51 & 3.23 & 3.41 & 3.42 & 3.73 & 3.87 & 4.52 \\
2 June 2013 & - & 0.73 & 0.46 & 0.28 & 0.27 & 0.21 & 0.18 & 0.26 & 0.54 \\
12 November 2014 & - & 0.27 & 0.18 & 0.15 & 0.12 & 0.15 & 0.19 & 0.21 & 0.33 \\
30 December 2014 & - & 3.04 & 1.86 & 1.11 & 1.01 & 1.10 & 1.64 & 2.24 & 3.12 \\
18 April 2014 & - & 0.31 & 0.15 & 0.06 & 0.06 & 0.08 & 0.08 & 0.10 & 0.19 \\
21 April 2015 & - & 1.73 & 1.05 & 0.72 & 0.86 & 0.74 & 0.64 & 0.70 & 1.06 \\
7 May 2105 & - & 0.74 & 0.55 & 0.37 & 0.33 & 0.25 & 0.18 & 0.17 & 0.35 \\
19 February 2016 & 0.01 & 6.49 & 4.44 & 5.26 & 7.13 & 5.89 & 4.81 & 4.84 & 6.35 \\
23 April 2016 & - & 0.86 & 0.65 & 0.40 & 0.33 & 0.17 & 0.10 & 0.12 & 0.33 \\
9 May 2016 & - & 0.34 & 0.31 & 0.18 & 0.14 & 0.08 & 0.05 & 0.05 & 0.12 \\
16 February 2017 & 0.02 & 13.92 & 8.82 & 9.35 & 13.29 & 12.97 & 10.09 & 10.62 & 14.65 \\
25 March 2017 & - & 5.60 & 3.30 & 2.93 & 3.83 & 3.88 & 3.84 & 4.23 & 5.53 \\
10 April 2017 & - & 2.47 & 1.57 & 1.32 & 1.85 & 1.84 & 1.79 & 1.85 & 2.25 \\
12 May 2017 & - & 0.68 & 0.50 & 0.35 & 0.49 & 0.45 & 0.42 & 0.45 & 0.58 \\
7 January 2018 & 0.01 & 4.99 & 3.76 & 4.54 & 6.54 & 6.45 & 5.20 & 4.87 & 5.32 \\
24 February 2018 & - & 4.73 & 3.29 & 3.24 & 4.34 & 4.03 & 3.86 & 3.96 & 4.56 \\
12 March 2018 & - & 2.45 & 1.56 & 1.22 & 1.55 & 1.36 & 1.39 & 1.56 & 2.08 \\
13 April 2018 & - & 0.94 & 0.76 & 0.69 & 1.12 & 0.82 & 0.53 & 0.55 & 0.75 \\
15 May 2018 & - & 0.57 & 0.32 & 0.21 & 0.21 & 0.18 & 0.23 & 0.38 & 0.63 \\
\hline
\end{tabular}

What is well-known that the zones turned towards the South in full sun are well exposed to the radiations solar and the zones turned towards North are with the shelters or the shade. Received energy on the surface of the ground varies according to the season according to the orientation and of the slope. In the mountains the oppositions between the snowing up of the slopes according to 
the exposure to the sun represent a major fact. During the spring the snow melt of the adrets occurs a few weeks before the snow melt of the ubacs. The ubacs are less exposed to the solar radiation than the adrets but the differences in received energy vary according to the slope and from the period of the winter (table 4).

The solar insolation (table 5) plays a part more important than the temperatures in the fusion of the coat. Generally, snow is permeable with the solar rays up to $10 \mathrm{~cm}$ or $15 \mathrm{~cm}$ of depth. When the layer of snow is too thin, the solar rays heat the ground and the snow melt will be accelerating on base of nival cover. The calorific contribution is conditioned by the albedo of snow-covered surfaces. When snow is fresh, considered solar energy accounts for approximately $80 \%$ of received energy. The albedo decreases up to $50 \%$ for old snows.

Table 5. Percentage of areas of solar insolation, $\mathrm{kwh} / \mathrm{m}^{2}$

\begin{tabular}{|c|cccc|}
\hline & \multicolumn{4}{|c|}{ Percentage of areas of solar insolation } \\
& \multicolumn{4}{|c|}{$\mathbf{( \mathbf { k h } / \mathbf { m } ^ { 2 } )}$} \\
Snow cover & $\mathbf{0 - 1}$ & $\mathbf{1 - 2}$ & $\mathbf{2 - 3}$ & $\mathbf{3 - 4}$ \\
\hline 27 December 2013 & 13.10 & 7.01 & 2.46 & 1.38 \\
21 March 2013 & 16.97 & 9.01 & 3.18 & 1.60 \\
2 June 2013 & 1.74 & 0.84 & 0.22 & 0.12 \\
12 November 2014 & 0.86 & 0.42 & 0.18 & 0.13 \\
30 December 2014 & 7.99 & 4.57 & 1.72 & 0.85 \\
18 April 2014 & 0.64 & 0.28 & 0.08 & 0.03 \\
21 April 2015 & 3.62 & 2.46 & 0.85 & 0.57 \\
7 May 2105 & 1.60 & 0.89 & 0.23 & 0.21 \\
19 February 2016 & 23.15 & 14.13 & 5.33 & 2.63 \\
23 April 2016 & 1.84 & 0.81 & 0.18 & 0.14 \\
9 May 2016 & 0.84 & 0.32 & 0.06 & 0.04 \\
16 February 2017 & 49.45 & 28.98 & 10.64 & 4.67 \\
25 March 2017 & 17.84 & 10.18 & 3.56 & 1.55 \\
10 April 2017 & 7.97 & 4.65 & 1.59 & 0.74 \\
12 May 2017 & 2.09 & 1.22 & 0.40 & 0.21 \\
7 January 2018 & 20.93 & 13.58 & 4.53 & 2.64 \\
24 February 2018 & 17.29 & 9.74 & 3.35 & 1.63 \\
12 March 2018 & 6.74 & 4.18 & 1.46 & 0.80 \\
13 April 2018 & 2.92 & 2.06 & 0.66 & 0.52 \\
15 May 2018 & 1.45 & 0.81 & 0.31 & 0.15 \\
\hline
\end{tabular}

The evaluation of snowmelt is not only important in the effective utilization of water resources and the forecasting of flood runoff, but it also influences climate through the change in ground surface properties. The amount of snowmelt can be predicted if the energy exchange through the snow surface can be evaluated. The principal terms of the energy exchange are solar radiation, atmospheric radiation, emission from the snow surface, wind speed... in this present study we have used the statistic model for evaluation the snowmelt (fig. 8).

As a final result of our study and based on NDSI index of the Landsat Oli images over five years by combining snow covers we built a prediction snow duration map of mount Lebanon, the snow duration on this map is not expressed in time but in melt speed from fast to slow with a gradient scale from red to blue the fast to slow melting speed on mount Lebanon.

According to this model it will be possible to know the regions that will be most vulnerable for snow melt, whether they will be exposed to meteorological parameters such as wind speed, high temperature, topographical dimension, exposure of slopes and orientation which play the major role for the melting and snow accumulation. 

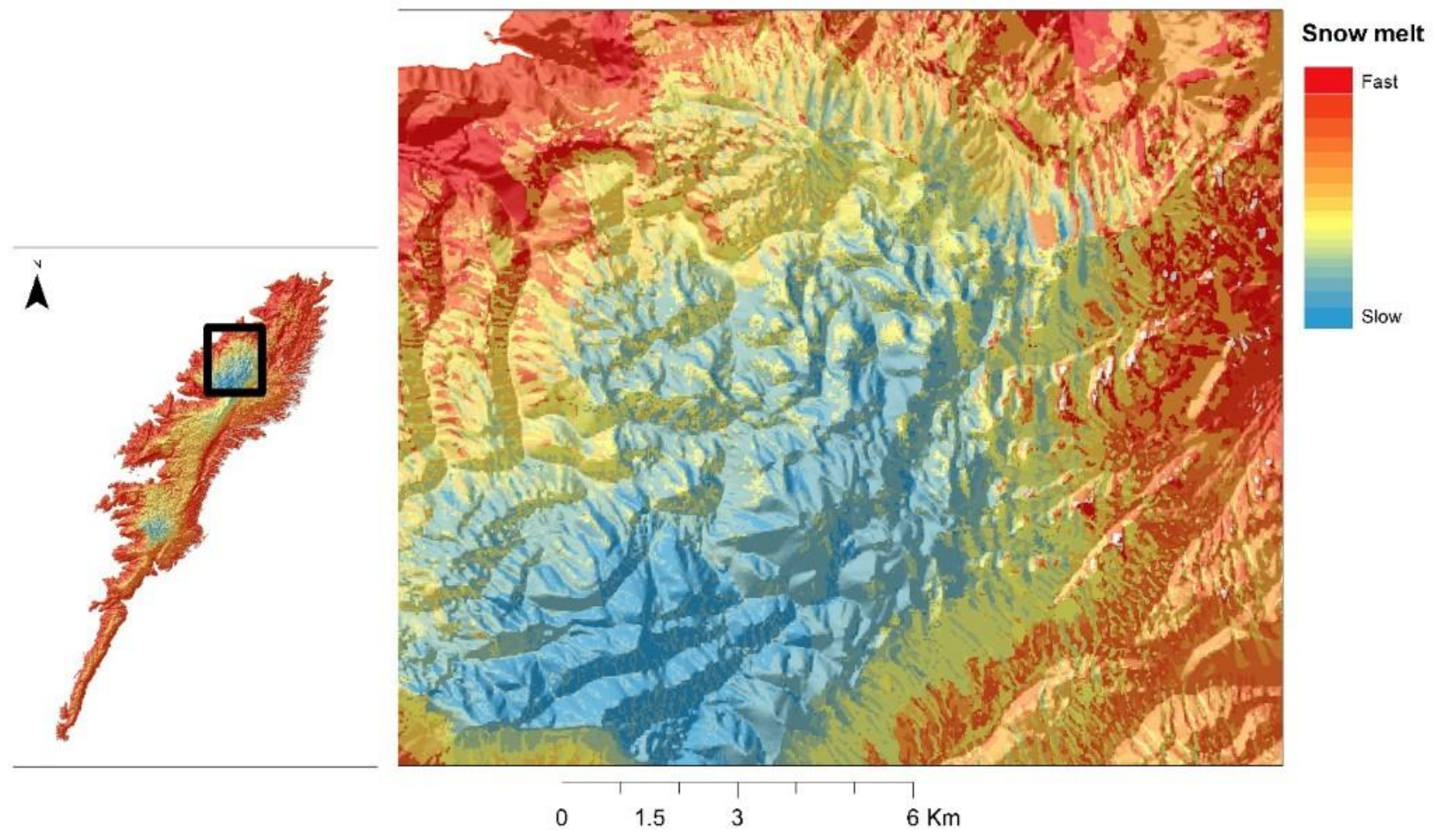

Fig.8. Snow duration map of mount Lebanon

\section{CONCLUSIONS}

In this paper, we demonstrated that snow cover could be mapped using Landsat 8 imagery with the application of NSDI index. Although the NSDI extracted snow cover at different date produced comparable results.

Lebanon is well-known in winter by the undulation of the Jet stream which will be able to draw thalwegs causing the invasions of the cold air above the tepid Mediterranean Sea, that will be able to reflect itself on the area by snowstorms sometimes on low altitudes. The results got according to the study of the satellite pictures representing different dates from the 2013 until 2018, showed that the surface of the snow-cover decreases around spring and it depends directly on the orientation of the slopes especially them which are in full sun and those which are with the shelters.

\section{REFERENCES}

1. Brown B.D., Braaten R.O. Spatial and temporal variability of Canadian monthly snow depths, 1946-1995. Atmospheric Ocean, 1998. V. 36. No 1. P. 37-54.

2. Doumit J.A. Snow cover boundaries detection from Landsat imagery on Lebanese mountains. Collection of scientific studies "Geographic studies of Krasnodar Region". Krasnodar: Kuban state University, 2017. Iss. 1 (11). P. 155-163.

3. Elder K., Rosenthal W., Davis R. Estimating the spatial distribution of snow water equivalence in a montane watershed. Hydrological Processes, 1998. V. 12. P. 1793-1808.

4. Hall D.K., Chang A.T.C., Foster J.L. Seasonal and interannual observations and modeling of the snowpack on the arctic coastal plain of Alaska using satellite data. Proceedings of the Cold Regions Hydrology Symposium. Fairbanks, AL: American Water Resources Association, 1987. P. 521-529.

5. Hall D.K., Riggs G.A., Salomonson V.V. Development of methods for mapping global snow cover using moderate resolution imaging spectroradiometer data. Remote Sensing of Environment, 1995. No 54 (2). P. $127-140$. 
6. Kulkarni A.V., Singh S.K., Mathur P., Mishra V.D. Algorithm to monitor snow cover using AwiFs data of RESOURCESAT-1 for the Himalayan region. International Journal of Remote Sensing, 2006. V. 27. No 12. P. 2449-2457.

7. Marofi S., Tabari H., Abyaneh H.Z. Predicting spatial distribution of snow water equivalent using multivariate non-linear regression and computational intelligence methods. Water Resources Management, 2011. No 25 (5). P. 1417-1435.

8. Smith R., Bonneau L., Lee X., Woo L., Fein F. Yale Guide to Landsat 8 Image Processing. Viewed 6 September 2013. Web resource: http://www.yale.edu/ceo/Documentation/Landsat\%208\%20image\%20processing.pdf (accessed 02.02.2018).

9. Tadono T., Nagai H, Ishida H., Oda F., Naito S., Minakawa K., Iwamoto H. Initial Validation of the 30 m-mesh Global Digital Surface Model Generated by ALOS PRISM. The International Archives of the Photogrammetry, Remote Sensing and Spatial Information Sciences, ISPRS, 2016. V. XLI-B4. P. 157-162. 10. Xiao X., Moore B., Qin X., Shen Z., Boles S. Large-scale observations of alpine snow and ice cover in Asia: Using multi-temporal VEGETATION sensor data. International Journal of Remote Sensing, 2002. V. 23. No 11. P. 2213-2228. 